\title{
CUIDAR E PESQUISAR: PRÁTICAS COMPLEMENTARES OU EXCLUDENTES?
}

\author{
Donizete Vago Daher ${ }^{1}$ \\ Fátima Helena do Espírito Santo ${ }^{2}$ \\ Cristina Lavoyer Escudeiro ${ }^{3}$
}

Daher DV, Santo FHE, Escudeiro CL. Cuidar e pesquisar: práticas complementares ou excludentes? Rev Latino-am Enfermagem 2002 marçoabril; 10(2):145-50.

Ao longo dos tempos, difundiu-se a concepção da Enfermagem empírica, estruturada no fazer, a qual se atualiza no cotidiano profissional, prejudicando a interdisciplinaridade entre cuidar, pesquisar e a construção de um saber específico que confira cientificidade às suas ações. Objetivamos conhecer as concepções dos enfermeiros sobre cuidar e pesquisar e analisar se essas práticas são complementares ou excludentes. Utilizamos observação participante e entrevistas semi-estruturadas com 10 enfermeiros de um hospital universitário, localizado no Estado do Rio de Janeiro. Os resultados apontaram discursos diferenciados sobre cuidar e pesquisar e, dificuldades em associar essas práticas que, para os enfermeiros, são, teoricamente, complementares e, no cotidiano profissional, excludentes.

DESCRITORES: pesquisa, enfermagem, conhecimento

\section{CARE AND RESEARCH: COMPLEMENTARY OR EXCLUSIONARY PRACTICES?}

The conception of empirical nursing has been disseminated, based on "doing", updated according to professional practice, impairing the interdisciplinarity between care, research and the building of a specific knowledge able to provide scientificity to its actions. Thus, authors aimed at understanding nurses' conceptions on care and research, analyzing their practices and verifying if they are complementary or exclusionary. They used participant observation and semi-structured interviews with nurses working at a University Hospital located in the state of Rio de Janeiro, Brazil. Results showed different discourses on care and research as well as the difficulties to associate these activities that, for nurses, are theoretically complementary but practically exclusionary.

DESCRIPTORS: research, nursing, knowledge

\section{CUIDAR Y INVESTIGAR: PRÁCTICAS COMPLEMENTARIAS O EXCLUYENTES?}

A través de los tiempos se difundió la concepción de la enfermería empírica, estructurada en el hacer, la cual se actualiza en el cotidiano profesional impidiendo la interdisciplinariedad entre cuidar, investigar y la construcción de un saber específico que confiera cientificidad a sus acciones. El objetivo del presente estudio es conocer las concepciones de los enfermeros sobre cuidar e investigar, analizar si éstas prácticas son complementarias o excluyentes. Utilizamos la observación participante y entrevistas semiestructuradas con enfermeros de un hospital universidad del Estado de Río de Janeiro. Los resultados mostraron discursos diferentes sobre cuidar e investigar y dificultades en asociar éstas prácticas que, para los enfermeros son teóricamente complementarias y en el cotidiano excluyentes.

DESCRIPTORES: investigación, enfermería, conocimientos

\footnotetext{
${ }_{1}^{1}$ Enfermeiro, Professor Adjunto, Mestre em Educação/UERJ, Doutorando em Saúde Coletiva FCM/UNICAMP, endereço: Rua: Presidente Backer, 337 - Ap. 901 - Icaraí - 24220-040 - Niterói - Rio de Janeiro - Brasil; ${ }^{2}$ Enfermeira, Professor Assistente, Mestre em Enfermagem/UFRJ, Doutoranda em Enfermagem EEAN/UFRJ; ${ }^{3}$ Enfermeira, Professor Assistente, Mestre em Enfermagem/UFRJ, Doutoranda em Enfermagem EEAN/UFRJ. Escola de Enfermagem Aurora de Afonso Costa da Universidade Federal Fluminense
} 
INTRODUÇÃO

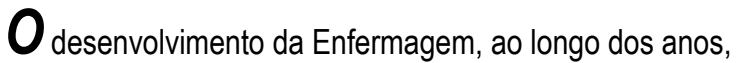
nos mostra uma trajetória de lutas por espaço e reconhecimento profissional. Muitas foram e ainda são as dificuldades enfrentadas pela profissão no que tange à construção de um saber específico que confira cientificidade às suas ações e visibilidade social.

No início do século XIX, toma lugar o paradigma cientificista na tentativa de superar a concepção mágico-religiosa vigente até então. Nesse período, surge, no campo da Enfermagem, Florence Nightingale, que sistematiza um campo de conhecimentos, instituindo "uma nova arte e nova ciência" para a qual é preciso uma educação formal, organizada com bases científicas.

Como arte, a enfermagem consiste no cuidar de seres humanos sadios e doentes cujas ações têm por base princípios científicos e administrativos e, como ciência, a enfermagem fundamenta-se no estudo e na compreensão das leis da vida. Assim, da arte e da ciência da enfermagem emergem suas ações que são entendidas como cuidar-educar-pesquisar, as quais estão interligadas e compõem as dimensões da atuação dos enfermeiros ${ }^{(1)}$.

Contudo, o modelo nightingaleano, marco inaugural da enfermagem moderna, também instituiu a hierarquização do trabalho, gerando, com isso, a dicotomia entre trabalho manual (fazer) e trabalho intelectual (saber) na profissão.

A concepção da Enfermagem como sendo uma profissão cujo conhecimento é estruturado em um fazer eminentemente prático ainda predomina, entretanto há significativos movimentos de mudança dessa concepção. O lugar hoje ocupado pela enfermagem como campo essencialmente prático parece não contemplar os anseios da categoria e, como tentativa para superar esse lugar, busca-se a compreensão da genealogia da profissão bem como a problematização de sua prática social e de seu objeto de trabalho.

A prática de cuidar como habilidade exclusiva ou predominantemente feminina é uma construção social, histórica e cultural cuja origem e constante atualização devem-se às diferentes instituições, em especial às instituições família e escola. Esta concepção é reflexo da divisão social e sexual do trabalho, pois "a sociedade delimita com bastante precisão, os campos em que pode operar a mulher, da mesma forma como escolhe os terrenos em que pode atuar o homem"(2).

O mundo social imprime nos sujeitos um modo de ser e de estar no mundo e este é diferenciado para homens e mulheres ${ }^{(3)}$. Pode-se afirmar, desse modo, que a sociedade imprime ou inculca na mulher um conjunto de valores que the confere uma performance específica.

Um estudo sobre o processo de construção da identidade profissional do enfermeiro constatou, em trabalho de campo, que a instituição família, de forma especial, contribui para uma certa "naturalização" das funções femininas, tal como a prática de cuidar, veiculando desde muito cedo características que vão gerar uma performance feminina, ou seja, uma identidade feminina única e inconfundivel ${ }^{(4)}$.

A genealogia da prática de cuidar mostra que a mesma teve seu início restrito ao espaço doméstico, privado, particular. Desse modo, é uma prática que teve sua origem no interior das famílias e, para sua realização, demandava apenas saber empírico, ou seja, um saber prático adquirido no fazer cotidiano, passando, assim, de geração a geração. Ao ser concebida como profissão de mulheres e para mulheres, a enfermagem foi incorporando a prática do cuidar enquanto campo de domínio próprio.

Nesse sentido, constata-se que a prática de cuidar está histórica e culturalmente conectada ao feminino, pois, ao longo dos anos, essa atividade esteve atrelada à trajetória desenvolvida pela mulher nas sociedades ocidentais modernas. Em contrapartida, a prática de pesquisar, ou seja, de criar novos conhecimentos, historicamente, tem sido concebida como prática masculina.

Considerando que acreditamos na interdependência do cuidar e do pesquisar no campo da enfermagem, resolvemos desenvolver este estudo que teve como propósito compreender as concepções dos enfermeiros sobre as práticas de cuidar e pesquisar, bem como analisar se essas práticas são complementares ou excludentes. Insere-se, assim, no movimento, cuja finalidade é contribuir para o processo de construção, socialização e legitimação do conhecimento da Enfermagem.

\section{MÉTODOS}

Optamos pelo estudo qualitativo e pela realização de trabalho de campo por acreditarmos que cada trabalho de campo possibilita repensar e fazer avançar nossa compreensão dos "fenômenos socioculturais" ${ }^{(5)}$ e, também, por ser um método capaz de oferecer as melhores condições de se captarem as concepções dos enfermeiros sobre as práticas de cuidar e pesquisar.

Para subsidiar todas as atividades do estudo, tomamos como base o que preconizam as normas éticas de pesquisa com seres humanos ${ }^{(6)}$.

A delimitação do campo da pesquisa, um hospital universitário localizado no Estado do Rio de Janeiro, deveu-se ao fato de as pesquisadoras nele desenvolverem suas atividades, fato que contribuiu para o surgimento de questionamentos referentes às práticas de cuidar e de pesquisar.

O trabalho de campo, realizado no período de janeiro a abril de 1999, constou de observação participante em unidades de 
internação clínica e cirúrgica do referido hospital e entrevista semiestruturada com 10 enfermeiros diaristas e plantonistas que atuavam nessas unidades.

A observação participante, desenvolvida durante o primeiro mês do estudo, perfazendo um total de 45 horas, além de favorecer a aproximação com o cenário e os sujeitos, também permitiu um estranhamento do que nos era familiar, ou seja, a rotina e o desenrolar das atividades dos enfermeiros enquanto prestavam cuidados aos clientes hospitalizados nessas unidades de internação.

Durante a observação participante, os enfermeiros dessas unidades mostraram-se receptivos e disponíveis quando expusemos os objetivos da pesquisa e esclarecemos que, nas entrevistas, suas identidades seriam preservadas pela utilização de nomes fictícios.

As entrevistas, gravadas em fita cassete, com duração média de 40 minutos, foram realizadas em uma sala reservada da própria unidade de atuação dos enfermeiros, tendo como questões orientadoras: 1) Fale sobre suas atividades diárias (o que faz, o que não consegue desenvolver, suas preocupações); 2) Como você se sente em relação ao seu trabalho como enfermeiro?; 3) Há outras atividades que você gostaria de desenvolver ? (quais, comente); 4) fale sobre a atividade de pesquisar (você faz, existe incentivo institucional, comente).

Durante o trabalho de campo, na medida em que os dados eram coletados, procedíamos, paralelamente, a sua análise, o que nos permitiu rever, continuamente, metas para as entrevistas consecutivas. Ao identificarmos que após a décima entrevista os dados começaram a ser repetitivos, concluímos que havíamos chegado ao "esgotamento", passando assim para a fase de análise dos mesmos.

\section{RESULTADOS E DISCUSSÃO}

Realizamos análise de conteúdo dos dados colhidos no trabalho de campo a fim de identificarmos os temas recorrentes os quais foram agrupados em categorias. Trabalhar com categorias significa agrupar elementos, idéias ou expressões em torno de um conceito capaz de abranger tudo isso ${ }^{(7)}$.

Com base na análise dos dados que emergiram do trabalho de campo, identificamos três categorias: A tangível prática de cuidar; A intangível prática de pesquisar; Cuidar e pesquisar como práticas complementares no discurso teórico e excludentes no cotidiano profissional.

Os dados colhidos nas entrevistas e durante as observações estão apresentados a seguir na Tabela 1, agrupados nas três categorias analisadas a seguir.
Tabela 1 - Categorias emergidas dos discursos

\begin{tabular}{|c|c|c|}
\hline $\begin{array}{c}\text { A tangível prática } \\
\text { de cuidar }\end{array}$ & $\begin{array}{c}\text { A intangivel prática } \\
\text { de pesquisar }\end{array}$ & $\begin{array}{l}\text { Cuidar e Pesquisar: } \\
\text { complementares no } \\
\text { discurso teórico e } \\
\text { excludentes no } \\
\text { cotidiano profissional }\end{array}$ \\
\hline $\begin{array}{l}\text { - máquina; } \\
\text { - robô; } \\
\text { - tecnicista; } \\
\text { - fria; } \\
\text { - solitíria; } \\
\text { - tarefa; } \\
\text { - serviço pesado; } \\
\text { - hierarquizado; } \\
\text { - mẫo na massa; } \\
\text { - depende da pessoa; } \\
\text { - ralaçẫo; } \\
\text { - abrangente; } \\
\text { - dificil; } \\
\text { - controle. }\end{array}$ & $\begin{array}{l}\text { - distante; } \\
\text { - intangível; } \\
\text { - coisa de docente; } \\
\text { - dá trabalho; } \\
\text { - nấo é reconhecida; } \\
\text { - nẫo tem retorno para } \\
\text { a prática; } \\
\text { - isolado; } \\
\text { - tem que estudar muito; } \\
\text { - busca pessoal e re- } \\
\text { conhecimento; } \\
\text { - nẫo receberam for- } \\
\text { maçẫo para a pesquisa. }\end{array}$ & $\begin{array}{l}\text { - complementarlexclu- } \\
\text { dente; } \\
\text { - conscientizaçẫo; } \\
\text { - distantes; } \\
\text { - concretohumano; } \\
\text { - influência histórico- } \\
\text { cultural; } \\
\text { - descontextualizaçẫo. }\end{array}$ \\
\hline
\end{tabular}

A tangível prática de cuidar

A maioria dos sujeitos da pesquisa mostrou que a prática de cuidar faz parte de seu cotidiano profissional. A prática de cuidar é concreta, tangível, e todos falam dela com total familiaridade, embora seja a mesma mecanizada, fragmentada e descrita como um trabalho pesado, duro, robotizado, que exige constantes improvisações.

Acho que trabalhar em um setor com pacientes graves vindos da emergência é complicado, muito pesado, e não sobra tempo para nada, a não ser trabalhar, trabalhar e trabalhar, feito uns robôs. (Enfo Murilo)

Temos que deixar de ser enfermeiros máquinas. $E$, para isso acontecer é preciso dar condições ao enfermeiro. (Enf ${ }^{a}$ Carmem)

0 Enfermeiro não tem condições de trabalho, ele tem que se adequar a uma escassez de material, materiais ultrapassados, e coisas que não funcionam ... ele tem que improvisar ... (Enfa Natália)

Nós pomos a mão na massa mesmo, o que acho que não acontece em setores mais tranqüilos. Meu setor tem tanto trabalho que, muitas vezes, não dá para fazer uma boa anotação no prontuário, dá apenas para cuidar e cuidar feito máquina. (Enfa Clara)

No cotidiano profissional, constatamos que os problemas relacionados com o exercício do cuidar, quer sejam eles técnicos ou administrativos, vão sendo solucionados com relativa naturalidade e certa tranqüilidade pelos enfermeiros, embora numa situação contínua de estresse, demonstrando com isso que há uma incorporação, na maioria da vezes inconsciente, do habitus do cuidar, adquirido durante a formação.

Ao analisar os sistemas de ensino, é apontado que a escola produz e inculca habitus específicos, propiciando aos que estão direta ou indiretamente a ela ligados, esquemas particulares de pensamento e de ação, que serão adotados em campos diferentes ${ }^{(3)}$. 
Na enfermagem contemporânea, o cuidado humano "resgata e discute a ampliação da arte de cuidar"(8), entretanto, tanto esse estudo como vários outros têm apontado uma prática de cuidar mecanizada, fragmentada e descontextualizada. Concordamos com a autora quando a mesma refere que o cuidar transcende essa visão, sendo um valor, um comportamento, uma filosofia, uma arte e uma ciência. Daí a necessidade de se buscar, na prática do cuidar, os objetos de estudo, e, com isso, a geração de conhecimento.

Para as autoras, ficou claro que, na cultura que orienta os enfermeiros que estão desenvolvendo sua prática profissional ligada à assistência direta a clientes, a prática da pesquisa não é percebida por eles como parte integrante do cotidiano profissional.

Nós colocamos a mão na massa mesmo, cuidamos mesmo, principalmente nos setores onde há pacientes com maior complexidade. (Enf ${ }^{a}$ Carmem)

A prática de cuidar é muito fria e tecnicista ... poucos são os que pensam em fazer algum trabalho cientifico. (Enfo Murilo)

Durante a observação nas unidades de internação, identificamos que, para esses enfermeiros, a ênfase era dada à prática mecanicista de cuidar, com base na realização de procedimentos técnicos de caráter rotineiro e ações administrativas para a organização hospitalar, as quais, muitas vezes, impedem o cuidado direto aos clientes. Essa concepção foi apontada nas entrevistas como aprendida durante a formação e cobrada na prática profissional.

Acho que muitos enfermeiros ficam ocupados com outras coisas durante o plantão, providenciando materiais, reposições de um modo geral, poucos são os que conseguem cuidar dos pacientes. (Enfa Paula)

A minha visão da Enfermagem, essa estrutura hierarquizada, compartimentada, departamentalizada, tarefeira, que a gente aprende na escola, é uma coisa que eu faço no meu dia-a-dia. (Enfa Natália)

No decorrer do curso de graduação, poucas estratégias ainda são utilizadas para estimular o desenvolvimento de pesquisas e a construção de novos conhecimentos, bem como para favorecer uma articulação entre os conhecimentos teóricos e os conhecimentos práticos, pelo contrário, parece que a prioridade continua sendo 0 desenvolvimento de habilidades motoras para a realização de técnicas, procedimentos e atributos comportamentais, inerentes a uma boa enfermeira ${ }^{(9)}$.

\section{A intangível prática de pesquisar}

O trabalho de campo mostrou que a prática de pesquisar está muito distante do cotidiano da maioria dos entrevistados. Eles explicitaram sua importância, entretanto não a vislumbraram como parte integrante do seu cotidiano profissional.

A prática de pesquisar apareceu, predominantemente, como investimento pessoal dos enfermeiros. É vista como uma prática distante, intangível, que possui um lugar demarcado, sendo esse lugar ocupado pelos enfermeiros que estão ligados ao ensino ou que possuem esse objetivo no futuro.

O número de enfermeiros que estão buscando a especialização, fazendo mestrado está aumentando (...) Eu tenho dúvida se esse retorno para o cuidado prestado está em primeiro lugar. Eu acho que é uma busca pessoal, uma busca de se firmar com conhecimento, não ficar uma pessoa mecânica, apenas um cumpridor de tarefas ... As pessoas estão buscando crescer para ocupar um espaço, para se mostrar no mercado bem qualificado ... Muitos, no futuro, querem a docência. (Enfa Gisele)

Tenho certeza de que a pesquisa e todos os trabalhos que forem realizados nas clínicas são de grande importância para a enfermagem, mas os enfermeiros que estão na assistência não pesquisam, isso é para quem está no ensino. (Enfa Ana)

Por que a pesquisa é vista, pelos entrevistados, como algo tão distante da prática profissional?

Nós não recebemos formação para o desenvolvimento da pesquisa, como parece que acontece com os novos enfermeiros.(Enf ${ }^{a}$ Carmem)

Eu comecei a pensar em fazer mestrado em Educação, achei que, se, de repente, eu fizesse mestrado, isso poderia me ajudar (...) Comecei a procurar saber como era e, quando soube, pensei 'não vou conseguir'. Por quê? Porque eu não exercitei isso ... Se eu tivesse desde o início dentro da minha formação, talvez eu tivesse me exercitado, e isso fosse fluir de uma forma mais tranqüila. (Enfa Gisele)

A pesquisa não faz parte do nosso cotidiano, da nossa realidade. Muitos enfermeiros têm vários empregos, não dá tempo para estudar, para dar atenção à família e até para relaxar. E também tem a seguinte questão: para quê vou fazer pesquisa? O que isso vai acrescentar para o meu trabalho? (Enfa Glória)

Sabemos que, nas primeiras décadas da trajetória da enfermagem brasileira, os conteúdos teórico-metodológicos eram muito pouco explorados, de forma sistemática, na formação dos enfermeiros, no sentido de dar embasamento à prática de pesquisar. Por isso, há que se refletir sobre as concepções histórico-culturais que atravessam a profissão, bem como sobre o processo de formação que, ainda hoje, fundamenta e instrumentaliza a prática profissional, para que, então, possamos vislumbrar a possibilidade de entrelaçamento entre o cuidar e o pesquisar.

A dualidade entre cuidar, como sinônimo de trabalho manual, realizado pelos profissionais que estão na assistência, e pesquisar, como sinônimo de trabalho intelectual, desenvolvido primordialmente pelos enfermeiros que estão no ensino, teve seu nascedouro nas instituições de formação, conferindo a esse profissional um perfil típico: competência técnico-científica, mas inabilidade para a prática de pesquisar.

As mudanças curriculares em curso, nas quais o ensino da 
pesquisa passa a ocupar um papel mais significativo entre as disciplinas, é um dos movimentos de mudança, além daquele assinalado pelos sujeitos deste estudo.

Cuidar e pesquisar como práticas complementares no discurso teórico e excludentes no cotidiano profissional

As práticas de cuidar e de pesquisar apareceram como práticas complementares e de importância para a maioria dos enfermeiros, sujeitos desse estudo. Entretanto, no cotidiano profissional, elas foram concebidas como práticas excludentes devido a diversos fatores dos quais destacamos: baixa valorização dada à pesquisa por parte dos próprios enfermeiros; pouco ou nenhum incentivo das instituições; reduzido conhecimento de métodos e estratégias para a prática de pesquisar; escassez de tempo e de recursos humanos e materiais.

Em seus depoimentos, Carmem e Paula foram claras sobre essas questões: Na teoria, é claro que acredito que cuidar e pesquisar devem andar juntos, um contribuindo com o outro, mas, na prática, isso não acontece de jeito nenhum. A gente só trabalha feito máquina. É preciso conscientizar tanto os enfermeiros como a instituição da importância dessa união. (Enfa Carmem)

O trabalho que iniciei há três anos sobre curativos em escaras, eu parei com tudo por falta de incentivo e também por falta de pessoal que dessem continuidade. Alguns membros da equipe médica reconheciam e valorizavam o trabalho, mas outros nem tomavam conhecimento. (Enfa Paula)

O modelo que orienta a formação dos profissionais de saúde e, em particular, do enfermeiro, bem como o conjunto de valores que norteiam a profissão, reflete numa concepção centrada no fazer técnico, como ilustra a fala de Gisele, ao se referir aos enfermeiros que estão pesquisando: ... eu não vejo assim buscando aquela coisa muito do concreto, curativo, do jeito que está a prática (...) não estão buscando assim a parte técnica, eles estão vendo mais esse lado humano e eu acho que esse retorno para a gente vai demorar um pouco, até porque as pessoas não têm essa cultura. A cultura diz assim: 'puxa, não tem esparadrapo, não tem gaze e você vai sentar para discutir isso?'(a humanização)". (Enfa Gisele)

Em contrapartida, para Carmem, os enfermeiros são: conscientes da importância da pesquisa para a enfermagem, acho que muitos enfermeiros são, mas dai a realizar algum tipo de trabalho científico vai muita distância ... (Enfa Carmem)

As falas dessas enfermeiras exemplificam e reforçam 0 pensamento de que na formação de recursos humanos, particularmente na formação de enfermeiros, "ao longo de sua história, percebem-se tendências oscilantes, priorizando ora o fazer, ora 0 pensar. Essa ambivalência tem a ver com a ideologia assumida pela intelectualidade orgânica enquanto responsável por essa formação e pelas definições dos modelos de práticas de saúde"(10).
Dessa forma, constatamos que há espaços delimitados, estanques, para as práticas de cuidar e de pesquisar, ou seja, para os entrevistados, existe, dentro da própria categoria dos enfermeiros, os que cuidam e os que ensinam e pesquisam, portanto a interdependência entre estas práticas é, no momento, inatingível.

\section{CONCLUSÕES}

As práticas de cuidar e de pesquisar: entrelaçamentos e separações

O trabalho de campo mostrou que ocorre, por parte da instituição, uma super valorização da prática de cuidar que se contrapõe à subvalorização da prática de pesquisar. A prática de cuidar aparece como atividade única e fim do enfermeiro e, dentro dessa concepção, ele foi formado. Em conseqüência, essa prática é apresentada pelos sujeitos como imposição, o que nos causou estranhamento, pois, enquanto instituição universitária, é formadora e socializadora de conhecimentos.

A prática de pesquisar ou mesmo a busca por atualização ou aprimoramento profissional aparece, em todas as falas, como investimento pessoal, ou seja, não há uma política institucional no sentido de alterar a concepção fragmentária do fazer. 0 que observamos em campo foram esforços das chefias de Enfermagem, no sentido apenas de adequar horários dos profissionais devido ao déficit de recursos humanos, o que facilita a realização de cursos e trabalhos de pesquisa. Mas, na concepção dos enfermeiros entrevistados, existe ênfase total na prática de cuidar em detrimento da prática de pesquisar, mesmo sendo o cenário um hospital de ensino que se propõe a gerar e divulgar conhecimentos.

No interior da categoria, em especial entre os enfermeiros assistenciais, sujeitos do estudo, pouco valor ainda é dado à prática de pesquisar, mas, a partir do momento em que a prática de cuidar for concebida pela enfermagem como uma "unidade valorativa"(8), científica e geradora de saber, terá visibilidade e será reconhecida pelos profissionais da saúde e pela sociedade.

Propomos, desse modo, que tanto as instituições de formação quanto as hospitalares incentivem a participação dos enfermeiros em cursos, núcleos e grupos de estudo e pesquisa, enfim, que se mobilizem no sentido de oportunizar condições básicas à criação de espaços onde estes possam se sentir estimulados a buscar o embasamento necessário para a realização de pesquisas, visando à geração de novos conhecimentos.

Para os entrevistados, há supremacia da prática de cuidar em relação à prática de pesquisar. Desse modo, cuidar e pesquisar aparecem como instâncias ou dimensões estanques, separadas, onde não há espaços para entrelaçamentos. Cabe aos próprios enfermeiros mudar essa concepção. 
Os dados coletados nas entrevistas mostraram, também, que a maioria dos enfermeiros trabalhava em mais de uma instituição, motivo alegado para realizarem poucas leituras e estudos, por falta de tempo, cansaço físico e mental. Contudo, alguns enfermeiros explicitaram que não vêem retorno das pesquisas realizadas por diversos enfermeiros, para a prática profissional, pois elas tratam de temáticas muito subjetivas, pouco aplicáveis ao dia-a-dia da enfermagem.

Trazemos essas questões nesse momento, no sentido de não se "culpar" somente a instituição pelos dissabores de não se pesquisar, pois, por mais normas e regras institucionais que existam cabe à sua comunidade a reflexão, tomada de postura e decisão acerca do que este grupo entende como necessário para transformações e mudanças. Além disso, não podemos ignorar a atual situação das instituições federais de saúde, que, em sua maioria, passam por um momento crítico, marcado por crise financeira, déficit de recursos materiais e humanos.

Acreditamos que chegou o momento de a enfermagem despir-se do modelo de formação no qual as práticas de cuidar e de pesquisar são, muitas vezes, entendidas como estanques, pois esse modelo já não contempla os anseios da categoria. Deve-se partir, de forma efetiva, em busca da formação de profissionais que sejam cuidadores e pesquisadores, que aprendam e saibam explorar as situações emergentes do cotidiano, da prática de cuidar, para elaborar suas problemáticas de estudo e reflexões, os quais, após relativizados e analisados, a ela voltem como subsídios.

\section{REFERÊNCIAS BIBLIOGRÁFICAS}

1. Silva AL. $O$ saber nightingaliano no cuidado: uma abordagem epistemológica. In: Waldow VR, Lopes MJM, Meyer DE. Maneiras de cuidar, maneiras de ensinar: a enfermagem entre a escola e a prática profissional. Porto Alegre (RS): Artes Médicas; 1995. p.4160.

2. Saffiotti HIB. A mulher na sociedade de classes: mito e realidade. Petrópolis (RJ): Vozes; 1987.

3. Bourdier P. Sistemas de ensino e sistemas de pensamento. In: Bourdier P. A economia das trocas simbólicas. $2^{\text {a }}$ ed. São Paulo (SP): Perspectiva; 1992. p. 203-29.

4. Daher V. Por detrás da chama da lâmpada: a identidade social do enfermeiro. Niterói (RJ): EdUFF; 2000.

5. Guedes SL. Jogo de corpo - um estudo de construção social de trabalhadores. Niterói (RJ): EdUFF; 1997.
A construção de um corpo de conhecimento específico do campo da enfermagem passa, também, pela superação da concepção vigente no campo de que a produção da enfermagem é apenas periférica ao campo da saúde.

Conforme salientamos anteriormente, a prática de cuidar em enfermagem deve ser retroalimentada pela prática de pesquisar, como forma de dar cientificidade e visibilidade a essa prática. Atualmente, observa-se que os estudos no campo da enfermagem mostram-se cada vez mais críticos e reflexivos, possibilitando, desse modo, melhor compreensão da profissão.

As instituições de formação de enfermeiros, as escolas de enfermagem, devem assumir a prática de cuidar e de pesquisar como práticas interdisciplinares, complementares e entrelaçadas, fazendo com que o enfermeiro as incorpore como habitus. Deve, deste modo, ocorrer total complementaridade, relacionalidade e reciprocidade entre a prática de cuidar e de pesquisar.

Por fim, mesmo sabedoras de que há vários outros estudos sobre essa temática, acreditamos na singularidade deste estudo, ao dar voz aos enfermeiros assistenciais, iniciativa que nos possibilitou, também, compreender que grande parte do conhecimento produzido por enfermeiros, tanto dos que estão atuando nas instituições de formação, quanto os que atuam na assistência, é pouco acessivel à grande parcela da categoria. Porém, este é mais um desafio a ser enfrentado e superado pelos enfermeiros no processo de construção, socialização e legitimação do conhecimento, no campo da enfermagem.

6. Ministério da Saúde (BR). Diretrizes e normas regulamentadoras de pesquisa envolvendo seres humanos. Brasília (DF): Ministério da Saúde; 1997.

7. Gomes RA. A Análise de dados em pesquisa qualitativa. In: Minayo MCS, organizadora. Pesquisa Social: teoria, método e criatividade. Rio de Janeiro (RJ): Vozes; 1994. p. 67-80.

8. Waldow VR. Cuidar/cuidado: o domínio unificador da enfermagem. In: Waldow VR, Lopes MJM, Meyer DE. Maneiras de cuidar, maneiras de ensinar: a enfermagem entre a escola e a prática profissional. Porto Alegre (RS): Artes Médicas; 1995. p. 7-30.

9. Espírito Santo FH. As interações entre professoras e estudantes na trama da construção da identidade profissional da enfermeira. [dissertação]. Rio de Janeiro (RJ): Escola de Enfermagem Anna Nery/ UFRJ; 1997.

10. Rezende ALM. Saúde: dialética do pensar e do fazer. $2^{\mathrm{a}}$ ed. São Paulo (SP): Cortez; 1989. 